\title{
The Concurrent Validity of Two Relational Selfhood Models: A Pilot Study
}

\author{
Luciano L’Abate ${ }^{1, *}$, Teresa Fiora Fornaciari ${ }^{2}$, Andrea De Giacomo ${ }^{3}$ and Francesco Craig ${ }^{3}$ \\ ${ }^{1}$ Georgia State University, Atlanta, Georgia USA \\ ${ }^{2}$ Cooperativa Socioeducativa "Il Sipario", Bari, Italy \\ ${ }^{3}$ Department of Child Psychiatry, University of Bari School of Medicine, Italy
}

\begin{abstract}
The purpose of this study was to evaluate the concurrent validity of two instruments: the Self-Other Profile Chart (SOPC) derived from one model of Relational Competence Theory (RCT) and the How You View Your Self (HYVYS) derived from the Elementary Pragmatic Model (EPM). These two instruments were administered together with the Brief Psychiatric Rating Inventory (BPRI) to two samples of women and men with and without psychiatric diagnoses. Scores in both instruments demonstrated statistically significant test-retest reliabilities and correlated highly with scores on the BPRI. These results tend to support the concurrent validity of both instruments and add more evidence to the theoretical significance of the models they represent.
\end{abstract}

Keywords: Elementary pragmatic model, selfhood models, brief psychiatric screening inventory, self-other profile chart.

\section{THE CONCURRENT VALIDITY OF TWO RELA- TIONAL SELFHOOD MODELS: A PILOT STUDY}

The purpose of this study was to evaluate the concurrent validity of two instruments, the Self-Other Profile Chart (SOPC) and the How You View Your Self (HYVYS) in relationship to the Brief Psychiatric Screening Inventory (BPSI). One reason for validating the SOPC lies in its being easy to administer and easy to score in minutes while the reason for validating the HYVYS lies in its being constructed for easy-toadminister and very-quick scoring for individual administration. This test was developed from the Elementary Pragmatic Model (EPM) developed by De Giacomo over decades of research and validation using ink-blots and eventually selected sentences. These administrations required meeting with a testadministrator that produced a time-consuming process. For instance, past research on the validity of the EPM consisted of hard-to-administer and difficult-to-score group administrations of ink-blots or selected sentences $[1,2]$.

Both instruments represent respectively two different relational models of Selfhood: one derived from Relational Competence Theory $[3,4,5]$ and the other from the Elementary Pragmatic Model [1]. Both models underscore the relational nature of the self viewed from two different theoretical viewpoints. Both theory-derived instruments, if valid, could be transformed into workbooks for Internet administration

"Address correspondence to this author at the 1800 Clairmont Lake, \#425, Decatur, GA 30033, USA; Tel: 404-353-1065; Fax: 404-633-9417

E-mail: llabate3@bellsouth.net through programmed distance writing where possible evaluation of therapeutic progress can be validated by either one of the two instruments, as suggested by [5].

\section{HISTORICAL BACKGROUND}

Historically, the Self has been an inferred construct since it was invented as an evolutionary substitute for another widely popular inferred construct called "Personality" [6]. Since personality could not be visible at the naked eye, different constructs attempted to take its hegemonic place. The construct of Self was one of them. Support for the Self construct was due to a variety of sources [7], mainly initiated and supported by Markus and Nurius's (1986) [8] seminal paper. The construct of Identity eventually replaced Self and Personality instead in a variety of recent sources [6, 9-12].

Contextually, the seductiveness of the Self construct was originally included as an important ingredient in family therapy $[12,5]$. However, on further reflection and support from various sources, this "Self" construct was given up for a more inclusive and empirically-supported construct of "identity". The reasons for this decline in popularity and usage was due to the possibility, that, in addition to its being an inferred construct, with an almost infinite number of selves possible, it was also an "orphan" construct, to the point that it did not belong to or derive from any specific psychological theory or model [6].

This, of course, was the case of many other inferred constructs such a "Self-esteem", or "Trust" among many others, including Identity, when multiple definitions 
and multi-dimensional qualities makes it difficult to include them in any empirically-verifiable theory. Eventually, the "identity" construct was included in this process as a more visible and empirically-verifiable and verified construct $[6,12-15]$.

Instead of the Self construct, Hooper et al., (2014) [16] argued that the construct of "role" is much more visible, controllable, and limited in its scope. There is a limited number of roles we all can play, record, and film, while the unmanageable number of selves leads to a confusing amalgam of generally non-specific possibilities [6]. Furthermore, roles can be manipulated in the laboratory because of their directly concrete presence, while the infinite number of selves makes it difficult is not impossible to manipulate them in the laboratory or in the clinic. In addition, by being more concrete and specific, roles can be considered and discussed with our participants, while the notion of Self is too abstract and generic to be meaningful in therapy sessions $[6,17]$.

\section{THE RELEVANCE OF RELATIONAL SELVES}

Within this brief contextual and historical background in mind, we needed to consider two Selfrelated models that in spite of both being admittedly inferred, that is: based on self-report, paper-and-pencil questionnaires, were not orphans. They are indeed directly derived from two very concrete, specific, verified, and verifiable models: Selfhood in Relational Competence Theory [3-5, 18] and from the Elementary Pragmatic Model (EPM) of De Giacomo [1, 2, 19].

The Selfhood Construct is one of the most verified models in RCT, as shown in Figure 1 as far as its reliability and convergent, criterion, and construct validities (Cusinato, 2012 [3], pp. 209-220; pp. 315-318 [18]; L'Abate et al. [4], 2010, pp. 163-188). It is based on the attribution and bestowal of importance to Self and intimate Others according to four possible relational propensities: (1) Self-fullness consists of the positive attribution and bestowal of importance to Self and Other, leading to adequate to superior functioning; (2) Selfishness consists of positive attribution and bestowal of importance to Self but negative attribution of importance to others, leading to acting out externalizations that, in their extremes, it may lead to murder; (3) Selflessness consists of positive attribution and bestowal of importance to Others but negative attribution and bestowal of importance to Self, leading to anxiety, depressions, and internalizations that, in their extremes, may lead to suicide; and (4) No-Self consists of negative attribution and bestowal of importance to both Self and Others, that, in its extremes, may lead to severe psychopathology.

Further external support for the validity of this relational Selfhood model is found in recent research results from the psychological science of money $[20,21]$. Participants who gave money away were much happier and were better adjusted than participants who kept money to themselves, i.e., "selfish" and were more likely to indulge in unethical behavior:

"Overall, it seems that money spent on purchases that are personally meaningful, or contribute to our sense of self, is going to produce greater hedonic returns, and choosing experiences over possessions is just one easy way to accomplish this (Carter, 2014, p. 235) [20].

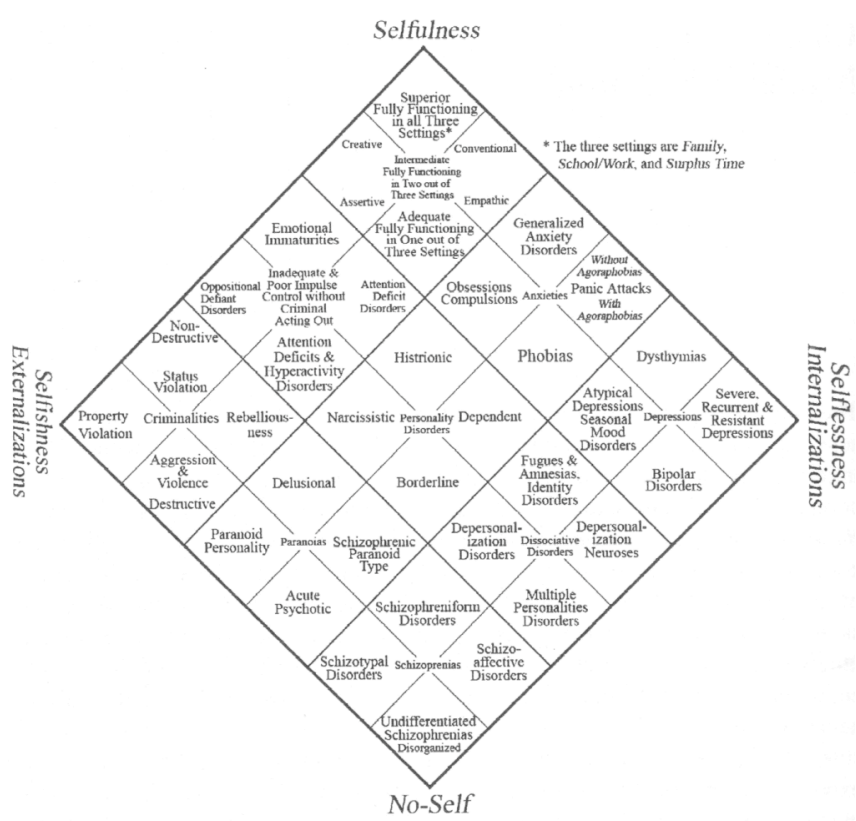

Figure 1: The selfhood model ${ }^{12}$ from relational competence theory (Cusinato and L'Abate, 2012 [3]; L'Abate and Cusinato, 2007 [18], 2011 [5]; L'Abate et al., 2010) [4].

The Elementary Pragmatic Model (EPM) was developed by De Giacomo decades ago on the basis of Gregory Bateson's thinking. It consists of 16 functions that cover as many human interactions as possible $[19,2]$. The relational nature of this questionnaire lies in asking participants to rate themselves on how they see themselves according to how many people are relationally involved in this view: all, many, some, none, and temporally in the past, present, and future.

This instrument thus far was created as a strictly experimental and introduced as a simpler and easier-to score than ink-blots or sentences. However, thus far, it 
lacked rigorous statistical support. Therefore, it was crucial to evaluate its reliability and its concurrent validity with two other established instruments, such as the SOPC and the BPRI by using adjectives that describe the 16 functions of the model.

Originally, both models were found to be related to the four-dimensional model developed originally from attachment theory (L'Abate, De Giacomo, McCarty, De Giacomo, \& Verrastro, 2000) [22].

Adjectives Definitions

0. Empty/Absent -Tabula Rasa in one's Mind

1. Participant/Sharer + Pure Sharing without ifs or buts

2. Solitary/Reserved - Keeping to oneself without sharing

3. Tenacious/Egocentric +Maintainer of one's worldview

4. Docile/Submissive - Passively obedient of others

5. Altruist/Involved +Acceptance of Another's worldview

6. Mysterious/Ambiguous -Doubtfully Insecure

7. Collaborative/Mediator + Finds solutions in differences

8. Abstract/Unpredictable -Completely outside reality

9. Sharer/Innovative + Seeking creatively concrete goals

10. Rebel/Antagonist -Opposition against any viewpoint

11. Dominant/Dictatorial - Either with me or against me

12. Two-faced/False altruist-Pseudo giver for his/her ends

13. Indirect/Unpredictable + Giving/getting extra-measure

14. Inconclusive/Disorganized - Inability to be straight

15. Confused/Chaotic-Inability to choose/select choices

Figure 2: The 16 functions of the how you view yourself test.

\subsection{The Brief Psychiatric Rating Inventory}

The Brief Psychiatric Rating Inventory (BPRI) includes 24 dimensions, each scored on a 7-point scale according to severity of each dimension, from nonpresent to extremely present. To patients the instrument was administered individually, in some cases as a structured interview with clinical observations of the behavior being considered, while with controls it was administered in groups.

The BPRI has a long history of validating studies as to its reliability and various validities. The 24 -item BPRI (version 4.0) enables the rater to measure psychopatho-logical severity [23]. Still, little thus far is known about the BPRI's reliability and validity outside of the psychosis spectrum. The aim of this study was to examine the factorial structure and sensitivity to change of the BPRI in patients with unipolar depression. Two hundred and forty outpatients with unipolar depression were administered the 24-item BPRI. Assessments were conducted at intake and at post-treatment in a Crisis Intervention Centre. An exploratory factor-analysis of the 24-item BPRI produced a six-factor solution labelled "Mood disturbance", Reality distortion", "Activation", "Apathy", "Disorganization", and "Somatization". The reduction of the total BPRI score and dimensional scores, except for "Activation", indicated that the 24-item BPRI is sensitive to change as shown in patients that appeared to have benefited from crisis treatment. The findings suggested that the 24-item BPRI could be a useful instrument to measure symptom severity and change in symptom status in outpatients presenting with unipolar depression.

Further support for the construct validity of the BPRI is found in the research by Lykke, Hesse, Austin, and Oestrich (2008) [24] whose aim was to evaluate its psychometric properties with the Beck Anxiety Inventory (BAI), and the Beck Depression Inventory $(B D I)$ in a sample of 134 patients with a substance use disorder and a non-substance related psychiatric disorder in a special inpatient dual diagnosis treatment unit. Participants were assessed at baseline. At discharge on average 6 months post-intake, $78 \%$ of patients were re-assessed using the same instruments. All instruments were tested in (1) their ability to discriminate patients with different diagnoses at baseline and follow-up using comparison of area under the curves, and (2) their temporal stability. Moderator regression was used to test whether thought disorder at baseline had any effect on the test-retest rank-order stability of other instruments. The BPRI Thought Disorder scale was able to discriminate between patients with and without schizophrenia spectrum diagnoses, and the BDI was able to discriminate between patients with and without mood disorders and schizoaffective disorders at intake to treatment, and each instrument was significantly better than the other at discriminating relevant diagnostic groups. Discriminant correlations between the $\mathrm{BDI}$ and the $\mathrm{BAl}$ were high and statistically significant. Moderator regression analyses showed no indication that any of the scales were less stable at higher levels of thought disorder. It was concluded that dual diagnosis patients can be reliably assessed for symptoms using the BDI and some items of the BPRI.

Brissos, Afonso, Cañas, Bobes, Fernandez, et al., (2013) [25] evaluated the satisfaction with life of schizophrenia outpatients and their caregivers as well as differences between patients with and without self-reported sleep complaints. They found that patients with schizophrenia often present sleep complaints, but its relationship with general satisfaction 
with life (SWL) and burden for caregivers has been understudied. The authors aimed to assess the differences in SWL between patients with and without self-reported sleep disturbances and that of their caregivers. In a noninter-ventional study, 811 schizophrenia adult outpatients were screened for their subjective perception of having (or not) sleep disturbances and evaluated with the BPRI and the Pittsburgh Sleep Quality Index (PSQI). Patients selfreporting sleep disturbances were significantly more symptomatic $(<0.001)$, presented significantly worse family support $(=0.0236)$, and self-reported worse SWL in all domains. Caregivers of patients with schizophrenia self-reporting sleep disturbances also reported worse SWL in all domains, as compared to caregivers of patients without subjective sleep disturbances. Patient and caregivers' SWL was significantly correlated to patients' quality of sleep ( < 0.0001 for all domains). Patient' and caregivers' SWL was negatively affected by patients' poor quality of sleep. Patients self-reporting sleep disturbances showed greater symptom severity, worse quality of sleep, worse SWL, and less caregiver support. SWL was also worse for caregivers of patients with schizophrenia reporting sleep disturbances.

The BPRS was designed and interpreted by the symptom dimensions to reflect mood disturbance, positive symptoms/apathy, bipolarity, and thought distortion/mannerism. Park, Jang, Kim, Jun, Lee, et al., (2015) [26] support the view that the BPRS may be a promising measuring tool for assessment of Major Depressive Disorders patients. In addition, the fourfactor structure of the BPRS may be useful in understanding the mood and psychotic characteristics of these patients.

\section{METHOD}

\subsection{Participants}

The clinical sample consisted of 44 participants: 4 patients referred to Child Neuropsychiatry and 40 Adult Psychiatry Units of University Hospital of Bari. Clinical diagnoses were accomplished according to DSM-IVTR. In the Psychiatric patients, $11.4 \%$ met the diagnostic criteria for Anxiety disorders, $11.4 \%$ for Bipolar Disorder, $29.5 \%$ for Borderline Personality Disorders, $9.1 \%$ for Paranoid Personality Disorders, $20.5 \%$ for Mood Disorder, $15.9 \%$ for Psychosis and $2.3 \%$ for Genetic Syndrome. Some were outpatients and some were recovered in the hospital. Patients recovered in the Psychiatric Clinic (Hospital) were characterized by the post-acute decompensating phase that was one step toward recuperating and bringing up the possibility of dismissal. Patients who were evaluated outside the Clinic and, therefore, nonhospitalized, were considered less severely dysfunctionally. Nonetheless, all patients, even if recovered, and therefore affected by major serious pathologies, such as schizophrenia or major depression, were in a phase of complete remission. Indeed, it was possible to evaluate patients not influenced by being in critical phases and diagnosed with psychiatric syndromes and / or personality disorders.

In regard to non-hospitalized patients, the evaluation was administered to those who were effected prevalently by non-extreme personality disorders. These necessary considerations took into focus that the whole battery of tests included an evaluation of self, even if sometimes the testadministrator might have provided a presence that may have effected a patient's answers. Nonetheless, most patients were lucid enough to express a judgment about themselves and indicate which score should be assigned for every single item. Obviously, a psychiatric patient in phase of crisis would not be able to use a critical capacity to answer to the test items. Adolescents in Pediatric Neuropsy-chiatry were sufficiently grown-up and collaborate willingly to complete each instrument and develop a vision of how to see themselves.

Exclusionary criteria included a history of a seizure disorder, mental retardation, progressive neurological problems, traumatic brain injury, or any other serious medical condition.

The control sample involved 77 volunteer students from the University of Bari matched on age $(p=0.26)$ and gender (Table 1). All clinical and control participants were fully informed about the nature and purpose of the research, all signing an Informed Consent Form after reading it.

\subsection{Procedure and Measures}

The three instruments were administered to the control sample in groups ranging from a dozen to a full classroom of about 30 participants. The administration of the whole battery took approximately 20 to 40 minutes for patients while its administration to controls 
took approximately no longer than 30 minutes. All three instruments were re-administered to the same participants after two weeks, with the sole exception of the HYYS. The list of adjectives at the left of Figure 2 was administered first while the list of adjectives on the right of Figure 2 was re-administered during the second administration.

As far qualitative extra test results are concerned, many patients during the administration of the whole battery commented freely about their own lives and their own emotions. Consequently, we can assert that the whole battery, in addition to its relevance to the lives of the patients, became also a motivational instrument to open up new ways to interact therapeutically with each patient. This unexpected outcome indicates how these instruments may possess a potential for adding programmed writing to the faceto-face verballybased interactions between participants and professionals. This unexpected outcome could not be present with the undergraduate control sample because the whole battery was administered in groups.

\section{RESULTS}

The major differences between the two samples were related to the educations levels and marital status.

Table 1: Characteristics of Samples

\begin{tabular}{|l|c|c|c|c|}
\hline & $\begin{array}{c}\text { Clinical } \\
\text { Sample(N=44) }\end{array}$ & $\begin{array}{c}\text { Control } \\
\text { Sample } \\
(\mathbf{N}=\mathbf{7 7})\end{array}$ & T-test & $\mathbf{p}$ \\
\hline \hline Gender & $52 \%$ & $42 \%$ & 1.28 & 0.26 \\
\hline Male & $48 \%$ & $58 \%$ & & \\
\hline Female & $23.82 \pm 8,8$ & $251 \pm 4,3$ & 1.92 & 0.06 \\
\hline Age & & & & Inizio \\
\hline $\begin{array}{l}\text { Educational } \\
\text { Level }\end{array}$ & $53 \%$ & $85 \%$ & & \\
\hline $\begin{array}{l}\text { High school } \\
\text { Fine modulo }\end{array}$ & $36 \%$ & $15 \%$ & & \\
\hline Middle school & $11 \%$ & - & & \\
\hline Degree & $7 \%$ & $2 \%$ & & \\
\hline Marital status & $7 \%$ & - & & \\
\hline Separated & $86 \%$ & $98 \%$ & & \\
\hline Married & & & & \\
\hline Single & & & & \\
\hline
\end{tabular}

As Table 1 shows the two groups are homogeneous for Gender $(p=0.26)$ and Age $(p=0.57)$.
In Table $\mathbf{2}$ there were statistically different scores on all the three measures between psychiatric patients and student controls.

Table 2: Differences between Samples

\begin{tabular}{|l|c|c|c|c|}
\hline & Clinical & Control & F & p-value \\
\cline { 2 - 5 } & Mean \pm Sd & Mean \pm Sd & & \\
\hline \hline HYVYS+ (T1) & $2.1 \pm 0.3$ & $2.29 \pm 0.3$ & 0.32 & $0.003^{*}$ \\
\hline HYSYS- (T1) & $1.32 \pm 0.5$ & $0.94 \pm 0.3$ & 15.98 & $0.0001^{*}$ \\
\hline HYSYS+ (T2) & $1.73 \pm 0.3$ & $1.94 \pm 0.5$ & 17.93 & $0.005^{*}$ \\
\hline HYSYS- (T2) & $1.41 \pm 0.4$ & $0.97 \pm 0.3$ & 9.91 & $0.0001^{*}$ \\
\hline BPRI(T1) & $2.27 \pm 1.1$ & $2.06 \pm 0.7$ & 19.07 & 0.172 \\
\hline BPRI(T2) & $2.13 \pm 1.08$ & $1.88 \pm 0.7$ & 10.15 & 0.096 \\
\hline SOPCSèlf (T1) & $7.98 \pm 1.2$ & $8.51 \pm 0.8$ & 0.87 & $0.006^{*}$ \\
\hline SOPCSèlf (T2) & $3.06 \pm 0.5$ & $7.97 \pm 1.4$ & 10.14 & $0.0001^{*}$ \\
\hline SOPCOthers (T1) & $7.42 \pm 1.2$ & $8.92 \pm 0.9$ & 0.07 & $0.0001^{*}$ \\
\hline SOPCOthers (T2) & $8.09 \pm 1.57$ & $8.63 \pm 1.74$ & 1.24 & $0.05^{*}$ \\
\hline
\end{tabular}

${ }^{*} p<0.05$ positive adjectives $(+)$; negative adjectives $(-)$.

In Table 3 there were statistically significant correlations for the clinical sample. The HYVYS showed a significant test-retest value as far as positive and negative adjectives were concerned. The concurrent validity of the positive adjectives in the HYVYS was indicated by its correlation with the SOPS both with the clinical sample in the first and second administration. These correlations suggest that the more positive one is about self (Self-fullness), the higher the ratings in all three instruments.

By the same token, the negative adjectives in the HYVYS correlated negatively with high scores on the $B P R I$, suggesting that this instrument is sensitive to negative views of the self.

In Table 4 the significant correlations in the control group, found that the HYVYS showed a acceptable test-retest scores in both positive and negative adjectives. These correlations indicate the validity of the test. In the HYVYS positive adjectives correlated with the SOPS in both the first and second administration, supporting the validity of Self-fullness representing the highest level of psychological functioning. The more positive one about Self and intimate others is, the higher the functioning. Scores on negative adjectives of the HYYS correlated with the BPRI in controls in both administrations. The lower one rates self the higher the scores on the BPRI. 
Table 3: Test-Retest Reliability for the Three Instruments: Correlations within the Clinical Sample ( $\mathrm{N}=44)$

\begin{tabular}{|c|c|c|c|c|c|c|c|c|c|c|}
\hline & $\begin{array}{c}\text { HYSYS } \\
+(T 1)\end{array}$ & $\begin{array}{c}\text { HYSYS } \\
\text {-(T1) }\end{array}$ & $\begin{array}{c}\text { HYSYS } \\
+(\text { T2 })\end{array}$ & $\begin{array}{c}\text { HYSYS } \\
-(\mathrm{T} 2)\end{array}$ & BPRI (T1) & BPRI (T2) & SOPC Sèlf(T1) & SOPC Sèlf(T2) & SOPC Other(T1) & SOPC Other(T2) \\
\hline \multirow{2}{*}{ HYSYS+(T1) } & & 0.11 & 0.29 & -0.1 & -0.14 & -0.002 & 0.28 & -0.009 & 0.14 & 0.009 \\
\hline & & 0.43 & $0.03^{*}$ & 0.47 & 0.3 & 0.99 & $0.04^{*}$ & 0.95 & 0.34 & 0.94 \\
\hline \multirow{2}{*}{ HYSYS-(T1) } & & & -0.05 & 0.41 & 0.29 & 0.07 & 0.14 & 0.05 & 0.36 & 0.03 \\
\hline & & & 0.71 & $0.002^{*}$ & $0.04^{*}$ & 0.57 & 0.29 & 0.71 & $0.01^{*}$ & 0.81 \\
\hline \multirow{2}{*}{ HYSYS+(T2) } & & & & 0.15 & -0.07 & 0.01 & -0.08 & 0.63 & -0.1 & -0.03 \\
\hline & & & & 0.26 & 0.59 & 0.91 & 0.53 & $0.0001^{*}$ & 0.47 & 0.79 \\
\hline \multirow{2}{*}{ HYSYS-(T2) } & & & & & 0.08 & 0.27 & -0.03 & 0.12 & 0.26 & 0.37 \\
\hline & & & & & 0.53 & $0.05^{*}$ & 0.83 & 0.37 & 0.07 & $0.007^{*}$ \\
\hline \multirow{2}{*}{ BPRI(T1) } & & & & & & 0.56 & -0.12 & -0.29 & -0.1 & -0.05 \\
\hline & & & & & & $0.001^{*}$ & 0.39 & $0.03^{*}$ & 0.5 & 0.68 \\
\hline \multirow{2}{*}{ BPRI(T2) } & & & & & & & -0.22 & -0.19 & -0.34 & -0.3 \\
\hline & & & & & & & 0.11 & 0.17 & $0.02^{*}$ & $0.03^{*}$ \\
\hline \multirow{2}{*}{ SOPCSèlf(T1) } & & & & & & & & -0.2 & 0.67 & 0.36 \\
\hline & & & & & & & & 0.98 & $0.0001^{*}$ & $0.008^{*}$ \\
\hline \multirow{2}{*}{ SOPCSèlf(T2) } & & & & & & & & 1 & 0.06 & -0.01 \\
\hline & & & & & & & & & 0.65 & 0.93 \\
\hline \multirow{2}{*}{ SOPCothers(T1) } & & & & & & & & & 1 & 0.04 \\
\hline & & & & & & & & & & 0.77 \\
\hline SOPCaltri(T2) & & & & & & & & & & 1 \\
\hline
\end{tabular}

${ }^{*} p<0.05$ positive adjectives $(+)$, negative adjectives $(-)$.

Table 4: Correlations Among the Three Instruments

\begin{tabular}{|c|c|c|c|c|c|c|c|c|c|c|}
\hline & $\begin{array}{c}\text { HYSYS } \\
+(\mathrm{T} 1)\end{array}$ & $\begin{array}{c}\text { HYSYS } \\
-(\text { T1) }\end{array}$ & $\begin{array}{c}\text { HYSYS } \\
+(T 2)\end{array}$ & $\begin{array}{l}\text { HYSYS } \\
-(\text { T2) }\end{array}$ & BPRI (T1) & BPRI (T2) & SOPC Sèlf(T1) & SOPC Sèlf(T2) & soPCOther(T1) & SOPCOther(T2) \\
\hline \multirow{2}{*}{ HYSYS+(T1) } & & -0.18 & 0.43 & -0.09 & -0.1 & -0.15 & 0.23 & 0.2 & 0.15 & 0.22 \\
\hline & & 0.05 & $0.0001^{*}$ & 0.34 & 0.29 & 0.12 & $0.01^{*}$ & $0.03^{*}$ & 0.1 & 0.01 \\
\hline \multirow{2}{*}{ HYSYS-(T1) } & & 1 & 0.22 & 0.44 & 0.39 & 0.32 & -0.17 & -0.14 & -0.15 & -0.15 \\
\hline & & & $0.02^{*}$ & 0.0001 & $0.0001^{*}$ & $0.001^{*}$ & 0.07 & 0.14 & 0.1 & 0.11 \\
\hline \multirow{2}{*}{ HYSYS+(T2) } & & & & 0.38 & 0.12 & 0.08 & 0.037 & 0.36 & -0.004 & 0.09 \\
\hline & & & & $0.0001^{*}$ & 0.19 & 0.39 & 0.71 & $0.01^{*}$ & 0.96 & 0.32 \\
\hline \multirow{2}{*}{ HYSYS-(T2) } & & & & & 0.27 & 0.24 & -0.08 & -0.09 & -0.1 & -0.11 \\
\hline & & & & & $0.004^{*}$ & $0.001^{*}$ & 0.41 & 0.32 & 0.28 & 0.22 \\
\hline \multirow{2}{*}{ BPRI(T1) } & & & & & & 0.74 & -0.27 & -0.15 & -0.21 & -0.22 \\
\hline & & & & & & $0.0001^{*}$ & 0.47 & 0.11 & $0.03^{*}$ & $0.02^{*}$ \\
\hline \multirow{2}{*}{ BPRI(T2) } & & & & & & & -0.1 & -0.8 & -0.17 & -0.18 \\
\hline & & & & & & & 0.29 & 0.41 & 0.06 & 0.05 \\
\hline \multirow{2}{*}{ SOPCSèlf(T1) } & & & & & & & & 0.54 & 0.4 & 0.35 \\
\hline & & & & & & & & $0.0001^{*}$ & $0.0001^{*}$ & $0.0001^{*}$ \\
\hline \multirow{2}{*}{ SOPCSèlf(T2) } & & & & & & & & 1 & 0.27 & 0.59 \\
\hline & & & & & & & & & $0.004^{*}$ & $0.0001^{*}$ \\
\hline
\end{tabular}


Table 4 continued..

\begin{tabular}{|c|c|c|c|c|c|c|c|c|c|c|}
\hline & $\begin{array}{c}\text { HYSYS } \\
\text { +(T1) }\end{array}$ & $\begin{array}{c}\text { HYSYS } \\
\text {-(T1) }\end{array}$ & $\begin{array}{c}\text { HYSYS } \\
\text { +(T2) }\end{array}$ & $\begin{array}{c}\text { HYSYS } \\
\text {-(T2) }\end{array}$ & BPRI(T1) & BPRI(T2) & SOPCSèlf(T1) & SOPCSèlf(T2) & SOPCOther(T1) & SOPCOther(T2) \\
\hline \hline \multirow{2}{*}{ SOPCPthers(T1) } & & & & & & & & & 1 & 0.62 \\
\cline { 2 - 9 } & & & & & & & & & & $0.000^{*}$ \\
\hline SOPC)thers(T2) & & & & & & & & & & 1 \\
\hline
\end{tabular}

$p<0.05^{*}$ positive adjectives $(+)$, negative adjectives $(-)$.

These samples are homogeneous for Gender $(p=0.26)$ and Age $(p=0.57)$.

\section{DISCUSSION}

These results show that the HYVYS overlaps significantly with the SOPC as well as with the BPRI, perhaps tapping a relational core-self-view that ranges from functional to dysfunctional extremes. For instance, using programmed writing; it is possible to evaluate the clinical validity of the Selfhood model through a specifically-derived series of written home-work assignments about Self-Other Importance (L' Abate, 2011a [27], pp. 579-585). A more general workbook about identity formation can be found in "Who Am I?" workbook (L’Abate, 2011a [27], pp. 696-707). Such specificity is difficult if not impossible to achieve faceto-face and verbally.

This is also an example of how models of RCT can be evaluated dynamically through Programmed Interactive Practice Exercises (PIPEs), linking evaluation with matched intervention (L'Abate, [17, 28]). In this regard, the growing influence of the Internet is determining how to help troubled people at the distance without ever seeing them face-to-face through talk 27-31 to 27-34 [27-31]. We are changing from an auditory-verbal to a visual-digital culture increasingly relying throughout the process of psychotherapy as consisting of programmed and targeted, written homework assignments (L' Abate, 2011a [27, 28, 31]. The major issue in such a development is whether online interventions will be structured or unstructured. The former are replicable and can be evaluated within each mental health professional and among different professionals. The latter cannot be replicable and cannot be evaluated because of their variability within each professional and among professionals [17].

However, structured, replicable approaches can be administered within a stepped-care framework (O'Donohue and Draper, 2011) [32], starting from the least invasive and least expensive approaches administered at a distance by para-professionals and moving to more complex and, therefore more expensive, approaches administered by fullycredentialed professionals (L'Abate, 2013b [33, 34, 31].

The HYVYS lends itself to clinically programmed applications using the same procedures to convert inert diagnostic instruments, factor analyses, descriptive adjectives, or psychiatric syndromes into dynamic PIPEs or workbooks Any list of single items found in most self-report, paper-and-pencil tests can be converted into workbooks by asking participants to define each item and give a couple of examples to illustrate concretely the initial definition. Once this nomothetic part is completed, respondents are asked to rank order the items according to how they apply to one self idiographically. This rank order serves as a treatment plan by having the top five or six items considered one by one with a general practice exercise that evaluates their histories, frequencies, durations, rates, intensities, consequences, and contexts (L'Abate, 2011a [27, 29, 17, 28, 31].

\subsection{Recommendations for Future Research}

Given the fairly straight-forward nature of our results, supporting the concurrent validity of both instruments and of the models that scaffold them, future research should focus on how both models and their instruments would correlate with other models of either RCT for the Self-Other Chart and for the Elementary Pragmatic Model for the HYVYS. For instance, it would be important to see whether Self-full individuals negotiate (Model 16) more effectively than either Selfish or Selfless individuals.

Another important RCT Model12 about Priorities should correlate well with Self-full individuals but not the Selfish or Selfless ones (Cusinato \& L'Abate, 2012 [3] L'Abate et al., 2010) [4]." For the HYVYS it would be important to see whether the ratio of positive to negative items would predict therapeutic outcome or correlate with other personality or relational instruments. One major issue for both instruments 
would relate to the presence and outcome of gender differences in research as well as in therapy.

\section{CONCLUSION}

The reliability and concurrent validity of both paperand-pencil self-report tests indicate who one can administer them both before and after any therapeutic or preventive interventions with individuals, couples, and adults family members. Their correlations with the BPRI suggest that these instruments can be administered with many different psychiatric clienteles because of their ease of administration and scoring.

\section{REFERENCES}

[1] L'Abate L and De Giacomo P. Improving intimate relationships: Integration of theoretical models with preventions and psychotherapy applications. Westport, CT: Praeger 2003; pp. 395-396.

[2] De Giacomo, P Mich L, Santamaria C, Sweeney LG and De Giacomo A. Information processing. In L. L'Abate (Ed.), Paradigms in Theory Construction. New York: SpringerScience 2012; pp. 341-363.

http://dx.doi.org/10.1007/978-1-4614-0914-4_18

[3] Cusinato M. A new version of the Self-Other Profile Chart. In M. Cusinato and L. L'Abate (Eds.), Advances in relational competence theory: With special attention to Alexithymia. New York: Nova Science Publishers 2012; pp. 209-220.

[4] L'Abate L, Cusinato M, Maino E, Colesso W, Scilletta C. Relational competence theory: Research and mental health applications. New York: Springer-Science 2010. http://dx.doi.org/10.1007/978-1-4419-5665-1

[5] L'Abate L and Cusinato M. Selfhood: A theory-derived relational model for mental illness and its applications. In $\mathrm{L}$. L'Abate (Ed.), Mental illnesses: Understanding, prediction, and control. Rijeka, Croatia: InTech Open Access Publications 2011; pp. 439-458.

[6] L'Abate L. Beyond the systems paradigm: Emerging constructs in family and personality psychology. New York: Springer-Science 2013a.

http://dx.doi.org/10.1007/978-1-4614-7444-9

[7] Dunkel C and Kerpelman J (Eds.). Possible selves: Theory, research, and applications. New York: Nova Science Publishers 2006.

[8] Markus $\mathrm{H}$ and Nurius $\mathrm{P}$. Possible selves. American Psychologist 1986; 41: 954-969.

http://dx.doi.org/10.1037/0003-066X.41.9.954

[9] Leary MR and Tangney JP (Eds.). Handbook of self and identity (2nd Edition). New York: Guilford 2012.

[10] Schwartz SJ, Luyckz K, Vignoles VL (Eds.). Handbook of identity theory and research: Domains and categories. New York: Springer-Science 2011a.

http://dx.doi.org/10.1007/978-1-4419-7988-9

[11] Schwartz SJ, Luyckz K and Vignoles VL (Eds.). Handbook of identity theory and research: Structures and processes. New York: Springer-Science 2011b. http://dx.doi.org/10.1007/978-1-4419-7988-9

[12] Cusinato $M$ and L'Abate L. Selfhood: A hidden ingredient in family therapy. Journal of Family Psychotherapy 2008; 19: 320-329. http://dx.doi.org/10.1080/08975350802475064

[13] L'Abate L. In search of a relational theory. American Psychologist 2009; 64: 776-788.

http://dx.doi.org/10.1037/0003-066X.64.8.779
Krueger RF, Hopwood CJ, Wright GC and Markon KE. DM-5 and the path toward empirically based and clinical useful conceptualization of personality and psychopathology. Clinical Psychology: Science and Practice 2014; 21: 245261.

http://dx.doi.org/10.1111/cpsp.12073

[15] Lilienfeld SO. DSM-5: Centripetal scientific and centrifugal antiscientific forces. Clinical Psychology: Science and Practice 2014; 21: 269-279

http://dx.doi.org/10.1111/cpsp.12075

[16] Hooper LM, L'Abate L, Sweeney LG, Gianesini G and Jankowski PJ. Models of psychopathology: Generational processes and relational roles. New York: Springer-Science 2014. http://dx.doi.org/10.1007/978-1-4614-8081-5

[17] L'Abate L. Concreteness and specificity in clinical psychology: Evaluations and programmed interactive practice exercises. New York: Springer-Science 2015a. http://dx.doi.org/10.1007/978-3-319-13284-6

[18] L'Abate $L$ and Cusinato $M$. Linking theory with practice: Theory-derived interventions in prevention and family therapy. The Family Journal: Counseling and Psychotherapy with Couples and Families 2007; 15: 318-327.

http://dx.doi.org/10.1177/1066480707303745

[19] De Giacomo P, L'Abate L, Margari F, Craig F and De Giacomo A. Diagnostic and therapeutic potential of the Elementary Pragmatic Model. Rivista di Psichiatria 2013; 48: 67-72.

[20] Carter TJ. The psychological science of spending money. In E. Bijleveld and H. Aarts (Eds.), The psychological science of money. New York: Springer-Science 2014; pp. 213-242. http://dx.doi.org/10.1007/978-1-4939-0959-9_10

[21] Meade NL and Stuppy A. Two sides of the same coin: Money can promote and hinder interpersonal processes. In In E. Bijleveld and $\mathrm{H}$. Aarts (Eds.), The psychological science of money. New York: Springer-Science 2014; pp. 243-262. http://dx.doi.org/10.1007/978-1-4939-0959-9 11

[22] L'Abate L, De Giacomo P, McCarty F, De Giacomo A and Verrastro G. Testing three models of intimate relationships. Contemporary Family Therapy: An International Journal 2000; 22: 103-122. http://dx.doi.org/10.1023/A:1007726717603

[23] Zanelloa A, Berthoudb L, Venturac J, Marco CG and Merlod MCD. The Brief Psychiatric Rating Scale (version 4.0) factorial structure and its sensitivity in the treatment of outpatients with unipolar depression. Psychiatry Research 2013; 210: 626-633. http://dx.doi.org/10.1016/j.psychres.2013.07.001

[24] Lykke J, Hesse M, Austin SF and Oestrich I. Validity of the $\mathrm{BPRI}$, the BDI, and the BAI in dual diagnosis patients. Addictive Behaviors 2008; 33: 292-300. http://dx.doi.org/10.1016/j.addbeh.2007.09.020

[25] Brissos J, Afonso P, Ca-as F, Bobes J, Fernandez IB and Guzman C. Satisfaction with life of schizophrenia outpatients and their caregivers: Differences between patients with and without self-reported sleep complaints. Schizophrenia Research and Treatment. Article ID 502172, 2013; pp. 3. http://dx.doi.org/10.1155/2013/502172

[26] Park SC, Jang EY, Kim D, Jun TY, Lee MS, Kim JM, Kim JB, Jo SJ and Park YC. Dimensional approach to symptom factors of major depressive disorder in Koreans, using the Brief Psychiatric Rating Scale: the Clinical Research Center for Depression of South Korea study. Kaohsiung Journal Medical Science 2015; 31: 47-54. http://dx.doi.org/10.1016/j.kjms.2014.11.001

[27] L'Abate L. Psychotherapy consists of homework assignments: A radical icono-clastic conviction. In $\mathrm{H}$. Rosenthal (Ed.), Favorite counseling and therapy homework techniques: Classic Anniversary Edition (pp. 219-229). New York: Routledge 2011a. 
[28] L'Abate L. Research on online/offline interventions in mental health: A critical review. New York: Nova Science Publishers 2015b.

[29] L'Abate L. Sourcebook of interactive practice exercises in mental health. New York: Springer-Science 2011b. http://dx.doi.org/10.1007/978-1-4419-1354-8

[30] L'Abate L. Recommended online computer-assisted treatments. In G. P. Koocher, J. C. Norcross, and B. A. Greene (Eds.), Psychologists' Desk Reference 3rd Edition (pp. 521-528). New York: Oxford University Press 2013c. http://dx.doi.org/10.1093/med:psych/9780199845491.003.01 $\underline{02}$
[31] L'Abate L. The golden rule and levels of awareness in clinical psychology. New York: Springer-Scicnce 2016.

[32] O'Donohue WT and Draper C. Stepped-care and e-health: Practical applications to behavior disorders. New York: Springer-Science 2011.

[33] L'Abate L. Clinical psychology and psychotherapy as a science: An icono-clastic perspective. New York: SpringerScience 2013b.

http://dx.doi.org/10.1007/978-1-4614-4451-0

[34] L'Abate L. Research on pre-para-post-therapeutic approaches in mental health: Prevention, promotion, psychotherapy, and rehabilitation. New York: Nova Science Publishers 2013d.

Received on 14-11-2015

Published on 31-12-2015

DOI: http://dx.doi.org/10.12974/2313-1047.2015.02.02.3

(C) 2015 L'Abate et al.; Licensee Savvy Science Publisher.

This is an open access article licensed under the terms of the Creative Commons Attribution Non-Commercial License (http://creativecommons.org/licenses/by-nc/3.0/) which permits unrestricted, non-commercial use, distribution and reproduction in any medium, provided the work is properly cited. 